\title{
Furcation Involvement
}

National Cancer Institute

\section{Source}

National Cancer Institute. Furcation Involvement. NCI Thesaurus. Code C82064.

Recession of the gum that exposes the furcation of a multirooted tooth. 